\title{
Study of Multi Layers Testing for Pavement
}

\author{
Sabaruddin ${ }^{1}$ \\ Department of Civil Engineering \\ Universitas Khairun \\ Ternate Selatan, Indonesia \\ ${ }^{1}$ sabaruddin.new@gmail.com
}

\author{
Muhammad Jamil ${ }^{2}$ \\ Department of informatics Engineering \\ Universitas Khairun \\ Ternate Selatan, Indonesia \\ 2jamil@unkhair.ac.id
}

\begin{abstract}
Multi layers in civil engineering has diverse meanings and uses for example on pavement has been used as a medium that provides theoretical information about the response of the pavement layer when receiving load in the middle, side and in the corner. In the other hand, multi-layers as a concept has been used as an approach in planning the thickness of road pavement added layer as the main principle of mechanistic method, and being part of the neural network method, also multi layers has been used as part of the road pavement analysis of the computational system with certain loading models. In this paper it is emphasized as an idea the need for multi layers to be appointed as a separate form of testing of the pavement layer, focuses on the literature review. The literature review uses an internalization-addition approach referring to the translation in the form of an interpretation of SNI 19-17025-2000 concerning the general requirements of laboratory testing and calibration laboratory requirements.
\end{abstract}

Keywords-multi layers; internalization-addition approach; SNI 19-17025-2000

\section{INTRODUCTION}

Indonesia, like an emerald in the equator, the country is endowed with natural resources preconditions such as aggregate, cement and bitumen which should be fully utilized as one solution to the premature destruction of the pavement (under design).

The phenomenon of early damage (under design) in flexible pavement construction since last two decades proves the shortcomings of conventional design and durability of the asphalt mix design results are vulnerable to structural damage, such as plastic deformation and material fatigue crack [1].

The effort to eliminate premature damage in Indonesia has started in the 70s, when started to use materials Asphalt Concrete (AC), but the use of air conditioning with a minimum thickness of pavement damage has not been established in the form of cracks. Furthermore, in the mid-80s, introduced Hot Roller Sheet (HRS) which has a high flexibility, a thicker asphalt membrane. Crack problems disappear, but new problems arise with the occurrence of permanent deformation, especially on roads with heavy traffic. In the 1990s introduced the use of Stone Matrix Asphalt / Split Mastic Asphalt (SMA), but is considered less successful because of the difficulty of mixing the cellulose fibers evenly in the mixture Split Mastic Asphalt. 2000s occurred against the development of Stone Matrix Asphalt Stone Matrix
Asphalt become Asbuton (SMAB), the results showed that the addition asbuton drainage can reduce the occurrence of bitumen so that it can replace the function of the cellulose fibers as stabilizers, also adding asbuton mixture increases the resistance to permanent deformation [2].

In era of the 2000s in addition to the development of Stone Matrix Asphalt by Pusjatan also conducted full-scale testing of porous asphalt on a road segment Jatibarang - Palimanan ( 30 600 - 31 050) towards Jakarta and Cirebon in the slow lane and fast lane, the northern coast of Java West, with a $5 \mathrm{~cm}$ thick layer of dense [3].

The description above is a partial effort in reducing early damage pavement, on the other hand there are events in the form of (traffic congestion, vehicle stop when the red lights, vehicles parked on top of the pavement, stopping the vehicle when taking a passenger, the vehicle stopped at the door toll, the vehicle stopped at the entrance of the airport exit, the vehicle stopped on the road, subgrade to the width of pavement, which gave the effect of its own (monotonic static) to the road pavement structure where the worst condition if at the time the incident took place there vehicles charged more.

The above conditions as well as a variety of related information into a source of inspiration importance of a form of testing that can reveal a phenomenon seen in general as well as flexible solutions. In this paper in question is a form of testing multi layers testing.

\section{METHOD}

As a literature review, the method that used is the internalization approach - an addition as part of the epistemology of science. According to Big Indonesian Dictionary, internalization namely the appreciation of a doctrine, doctrine, or the value of that is the confidence and awareness of the truth or value manifested in attitudes and behavior. another understanding of internalization is the effort to appreciate and explore value, so that it is embedded in every human being. From the definition of internalization as well as the addition above, the authors conclude internalization approach - an addition that efforts to create a multi-layer into a shape of its own testing with less add some significant things into multi-layer theory, in order to implement the translation of SNI 19-17025-2000 [4] 


\section{RESULT AND DISCUSSION}

The multi-layer or elastic theory is the main principle of the mechanistic method of calculation [5]. This concept assumes that each of pavement has properties such as homogeneous, isotropic and linear elastic which means it will return to its original shape when the load is moved. In modeling pavement road with this elastic layer model input data required to determine the stress and strain on the pavement structure and response to load. The parameters used were:

Parameters of each layer. Parameters layer is meant, among others, are as follows:

a. Modulus of elasticity

b. Poisson ratio

c. The thickness of each layer

d. Load conditions

In this method the work load of the vehicle above the pavement structure is considered as a static load evenly, then there will be stress and strain on the structure. Voltage, strain, and deflection is the response of pavement material which experienced loading. Calculation of the response voltage, strain, and deflection at each layer for a pavement is extremely complex requiring extremely high accuracy that will be tricky done manually for the necessary calculations using computer assistance. The use of computer tools should also be the time of data collection.

The layered elastic media described as the picture. 1 and used as the basis of a physical model of the pavement system [6].

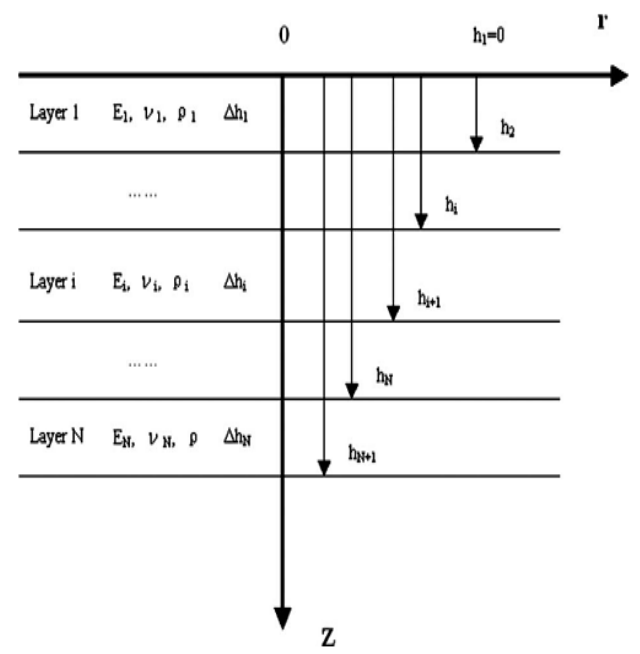

Fig. 1. Medium Multi layer

Should be understood that the multi-layer theory strung from a variety of theories, among others:

1) Theory Boussinesq: The assumption: pavement and subgrade is homogeneous and isotropic linear elastic modulus of elasticity (E), and Poisson's ratio $(\mu)$ as a result of the static concentrated load on the surface of the pavement [7].
A series created by Boussinesq equation to determine stresses, strain and deformation. The illustrations can be seen in Figure 2.

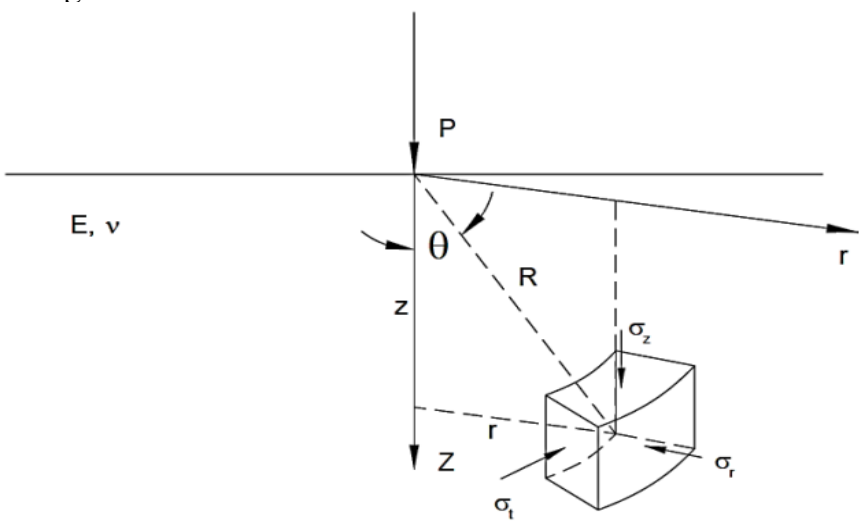

Fig. 2. The axis coordinate system for Boussinesq equation.

Several Boussinesq equation shown in the equation below, where:

$$
R=\sqrt{z^{2}+r^{2}}
$$

Normal stress:

$$
\sigma z=\frac{3 P}{2 \pi R^{2}} \cos ^{2} \theta
$$

$$
\begin{gathered}
\sigma r=\frac{P}{2 \pi R^{2}}\left[\cos \theta \sin ^{2} \theta-\frac{1-2 \mu}{1+\cos \theta}\right] \\
\sigma t=\frac{(1-2 \mu) P}{2 \pi R^{2}}\left[-\cos \theta+\frac{1}{1+\cos \theta}\right]
\end{gathered}
$$

Shear stress

$$
\begin{gathered}
\operatorname{Tr} z=\frac{3 P}{2 \pi R^{2}} \cos ^{2} \theta \sin \theta \\
\operatorname{Tr} z=0
\end{gathered}
$$

Normal strain

$$
\begin{gathered}
\varepsilon z=\frac{(1+\mu) P}{2 \pi R^{2} E}\left[3 \cos ^{3} \theta-2 \mu \cos \theta\right] \\
\varepsilon r=\frac{(1+\mu) P}{2 \pi R^{2} E}\left[-3 \cos ^{3} \theta+(3-2 \mu) \cos \theta-\frac{1-2 \mu}{1+\cos \theta}\right] \\
\varepsilon t=\frac{(1+\mu) P}{2 \pi R^{2} E}\left[-\cos \theta+\frac{1-2 \mu}{1+\cos \theta}\right]
\end{gathered}
$$

Displacements

$$
d z=\frac{(1+\mu) P}{2 \pi R^{2} E}\left[2(1-\mu)+\cos ^{2} \theta\right]
$$




$$
\begin{gathered}
d r=\frac{(1+\mu) P}{2 \pi R E}\left[\cos \theta \sin \theta-\frac{(1-2 \mu) \sin \theta}{1+\cos \theta}\right] \\
d t=0
\end{gathered}
$$

in the above equation, the elastic modulus does not have any influence on the stress and strain of normal and shear stresses. The next Boussinesq equations developed by researchers with the load evenly.

2) Burmister Theory (1945)/theory of two layers: The assumption pavement consists of two layers:

- Pavement

- Subgrade

- The top layer and bottom layer are homogeneous, elastic and isotropic

- Great rigidity against the rigidity layer on the bottom layer,the ratio give a decisive influence.

Formula:

$$
D=1.5\left(\frac{p \cdot a \cdot F_{2}}{E_{2}}\right)
$$

where,

$D=$ deflection

$p=$ load evenly split $(\mathrm{Pa})$

$a=$ radius of the circle $(\mathrm{cm})$

$F_{2}=$ coefficient of deflection, depending $\mathrm{E}_{1} / \mathrm{E}_{2}$

$E_{2}=$ modulus of elasticity of the soil (Pa)

3) Theory of Westergaard (1926): The theoretical analysis slab laid on the ground that burdened wheel vehicles and Stress occurs analyzed. The assumption:

- slab is homogeneous, isotropic, and elastic

- subgrade elastic (the vertical direction)

- due to load, subgrade reaction vertical direction and magnitude

- to proportioned slab elastic deflection load evenly split,

- with the contact area of a circle and an ellipse

Westergaard made form analytical solutions approach for stress and deflection on rigid pavement with illustrations (figure 3) and the following formula.

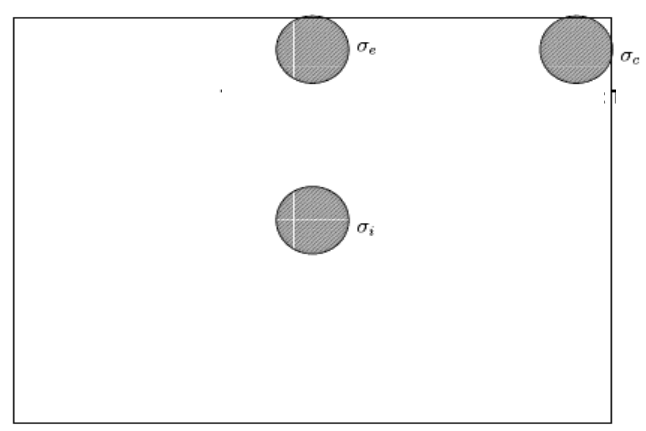

Fig. 3. Three loading conditions Westergaard theory

corner loading

$$
\begin{gathered}
\sigma c=\frac{3 P}{h^{2}}\left[1-\frac{\alpha \sqrt{2}}{l}\right]^{0.6} \\
\Delta c=\frac{P}{k l^{2}}\left[1.1-0.88\left(\frac{\alpha \sqrt{2}}{l}\right)\right]
\end{gathered}
$$

interior loading

$$
\sigma i=\frac{3(1+\mu) P}{2 \pi h^{2}}\left[\ln \frac{l}{b}+0.6159\right]
$$

Where:

$$
\begin{gathered}
b=a, \text { if } a>1.724 h \\
b=\sqrt{1.6 a^{2}+h^{2}-0.675 h}
\end{gathered}
$$

if,

$$
a<1.724 h
$$

$$
\Delta i=\frac{P}{8 k l^{2}}\left[1+\frac{1}{2} \pi\left[\ln \left(\frac{a}{2} l\right)-0.673\right]\left(\frac{a}{l}\right)^{2}\right]
$$

edge loading,

$$
\begin{gathered}
\sigma e=\frac{3(1+\mu) P}{\pi(3+\mu) h^{2}}\left[\ln \left(\frac{E h^{2}}{100 k a^{4}}\right)+1.84-\frac{4 \mu}{3}+\frac{1-\mu}{2}+\frac{1.18(1+2 \mu) a}{l}\right] \\
\Delta e=\frac{\sqrt{2+1.2 \mu P}}{\sqrt{E h^{3} k}}\left[1-\frac{(0.76+0.4 \mu) a}{l}\right]
\end{gathered}
$$

The other side is required for the addition of the results of an empirical approach as a helper to define theoretically cause and effect relationship right from the phenomenon. Or in other words to establish the context of the multi-layers at the level of correlation of input-process - output and results of the management context. The empirical method as a design approach that is based on the results of the experiment or 
experience, in which observations are used to establish the correlation between the input and the results of process. The empirical method was developed based on the experience of existing research. By him the necessary steps observation that definitely requires major equipment and support as well as software to facilitate the gathering of data on the observation proficiency level [5]. The equipment according to the following picture:

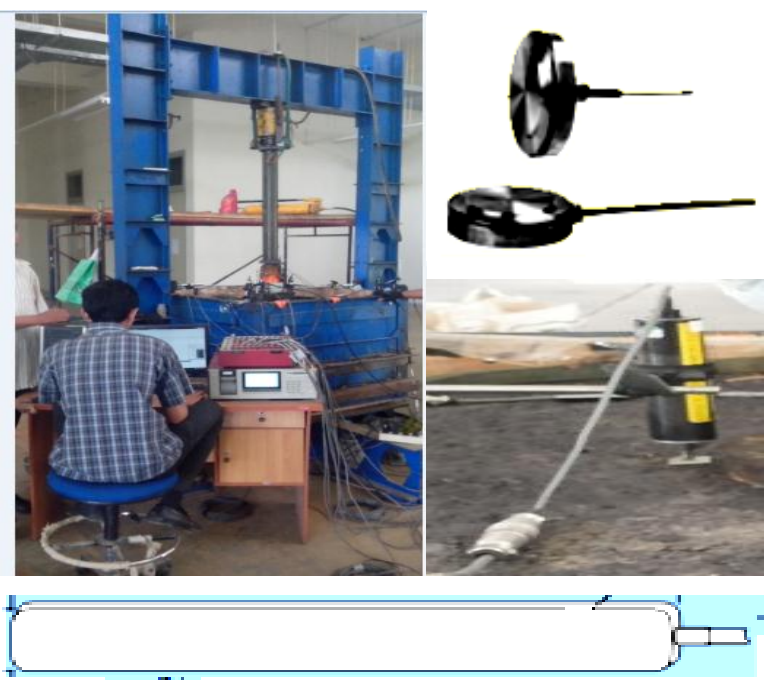

Fig. 4. The multi-layer test tool

It inspires a multi-layers used as a form of its own testing to obtain preliminary information on the early symptoms of damage to road pavement including previous research as follows:

TABLE I. RELEVANT RESEARCH

\begin{tabular}{|c|c|c|c|}
\hline Researchers & Title & Objects & Test Results \\
\hline $\begin{array}{l}\text { Hary } \\
\text { Christady } \\
\text { Hardiyatmo }\end{array}$ & $\begin{array}{l}\text { Naileb Slab } \\
\text { for } \\
\text { Strengthening } \\
\text { Concrete } \\
\text { Plates on } \\
\text { Rigid } \\
\text { Pavement }\end{array}$ & $\begin{array}{l}\text { concrete plate } \\
50 \times 50 \mathrm{~cm} \text { and } \\
70 \times 70 \mathrm{~cm}, 10 \\
\mathrm{~cm} \text { thick with } \\
\text { and without } \\
\text { poles there are } \\
\text { placed on the } \\
\text { ground. }\end{array}$ & $\begin{array}{l}\text { The average } \\
\text { deformation on } \\
\text { specimen without } \\
\text { poles with } \\
\text { dimensions of } \\
50 \times 50 \mathrm{~cm} \text { is } 3: 39 \\
\mathrm{~mm} \text { while the } \\
\text { dimensions are } \\
70 \times 70 \mathrm{~mm} 2.54\end{array}$ \\
\hline $\begin{array}{l}\text { Luca G. } \\
\text { Sorelli, dkk }\end{array}$ & $\begin{array}{l}\text { Steel Fiber } \\
\text { Concrete } \\
\text { Slabs on } \\
\text { Ground: A } \\
\text { Structural } \\
\text { Matter }\end{array}$ & $\begin{array}{l}\text { A Matter } \\
\text { Structural } \\
\text { concrete plate } \\
300 \times 300 \mathrm{~cm} \\
\text { with } 15 \mathrm{~cm} \\
\text { thick is placed } \\
\text { on the } \\
\text { placement is } \\
\text { made of steel as } \\
\text { many as } 64 \\
\text { pieces }\end{array}$ & $\begin{array}{l}\text { the average } \\
\text { deformation on } \\
\text { specimen without } \\
\text { steel fiber is } 2 \mathrm{~mm}\end{array}$ \\
\hline
\end{tabular}

\section{Conclusion}

Multi-layer testing deserves to be improved because the standard test device performed has fulfilled the context as a separate test. This test can provide initial information to reduce early damage from the road pavement.

\section{REFERENCES}

[1] M. Wahyudi, "Studi Praktis Konsep Zona Terlarang Campuran Agregat Gradasi Menenrus Supervave”, J. Din. Tek. Sipil, vol. 11, pp. 143-150, 2011.

[2] N. Suaryana, "Kajian Material Stone Matrix Asphalt Buton Berdasarkan Kriteria Deformasi Permanen," [Online], Available: www.pu.go.id/ uploads/services/service20130717131250.pdf. [Accessed: 23-Aug-2018]

[3] Iriansyah, "Laporan Kajian dan Pengawasan Uji Coba Skala Penuh Teknologi SMA dan Porous asphalt," Kementerian Pekerjaan Umum, Badan Penelitian dan Pengembangan, Pusat Litbang Jalan dan Jembatan, Bandung, 2010.

[4] SNI 19-17025-2000, Persyaratan Umum Kopetensi Laboratporium Pengujian dan Laboratorium Kalibrasi (Full Adoption of ISO/IEC 17025, 2000

[5] F. Khairi and A.A. Muis, "Evaluasi perencanaan tebal perkerasan lentur metode bina marga Pt T-01-2002-B dengan menggunakan program kenpave”, J. Tek. SIpil, vol. 2, pp. 1-10, 2013.

[6] L. Sun, F. Luo, and W. Gu, "Elastodynamic Inversion of Multilayered Media via Surface Waves-Part I: Methodologies", J. of Appl. Mech., vol. 78, pp. 041005-041005-7, 2011.

[7] W. Tu, Response Modelling of Pavement Subjected to Dynamic Surface Loading Based on Stress-Based Multi-Layered Plate Theory.The Ohio State University, Columbus, Ohi, 2011.

[8] H. C. Hardiyatmo, "Sistem "Pelat Terpaku" untuk Perkuatan Pelat Beton pada Perkerasan Kaku (Rigid Pavement)", Makalah Seminar Nasional Teknologi Tepat Guna, Penanganan Sarana Prasarana Indonesia, Yogyakarta 12 April 2008.

[9] G.S. Luca, "Steel Fiber Concrete Slabs on Ground: A Structural Matter," [Online], Available: www.concrete.org /publications/internationalconcr eteabstractsportal/m/.../16431. [Accessed: 18-Aug-2018].

[10] Sabaruddin, et al, "Testing Multi Layer on The Road Pavement," Proc. of the 2nd Makassar Int. Conf. on Civil Eng. Makassar, pp. 307-312, August 2015.

[11] Sabaruddin, T.W. Ali, N.D.J. Rudy, "Pengujian Multilayer pada Perkerasan Jalan,” Prosiding Seminar Nasional-ITM, 2015.

[12] Sabaruddin, et all, "Multi Layer Testing Experimental Study On Pavement Made Of Porous Asphalt And Concrete", ARPN J. of Eng. and Appl. Sci., vol. 11, pp. 7174-7179, 2016

[13] Sabaruddin, "An Exprimental Study of MultiLayer Testing on Pavement made of Porous asphalt and Concrete", UNHAS, 2017 